\title{
PERAN PEMERINTAHAN DESA MENANGGULANGI KEMISKINAN DENGAN PROGRAM JALAN LAIN MENUJU MANDIRI DAN SEJAHTERA
}

\author{
Cahyo Sasmito ${ }^{1)}$, Natalia Sopiana ${ }^{2)}$ \\ ${ }^{1,2}$ Program Studi Administrasi Publik, Fakultas Ilmu Sosial dan Politik \\ Universitas Tribhuwana Tunggadewi \\ email: sofianaokta97@gmail.com
}

\begin{abstract}
Abstrak: Permasalahan kemiskinanmenjadi masalah utama pemerintahan pusat hingga pemerintahan daerah untuk menanggulangi kemiskinan tersebut, sampai akhirnya dibuatlah Progran Jalan Lain Menuju Mandiri Dan Sejahtera (JALIN MATRA) dengan kelompok sasarannya adalah kepala keluarga perempuan. Programpemerintahanpusat ini sesuai dengan ProgramPemerintahan Provinsi Jawa Timur untukmelaksanakan pembangunan berkelanjutan yang fokusnya rakyat miskin, sasarannyaadalah Kepala Rumah Tangga Perempuan. Penelitian ini menggunakan metode kualitatif, Teknik Pengumpulan Data; observasi, wawancara, dan dokumentasi. Teknik Penentuan Informan:purposive sampling. Analisis Data:melalui reduksi data, penyajian data, dan penarikan kesimpulan/verifikasi. Teknik Menguji Keabsahan Data: triangulasi. Hasil Penelitian ini menunjukkan:Peran pemerintahan desa dalam menanggulangi kemiskinan dengan melaksanakan Progran Jalan Lain Menuju Mandiri Dan Sejahtera (JALIN MATRA) yang didukung dengan pendanaan/anggaran, fasilitas sarana, dan prasarana berupa peralatan yang sesuai dengan usaha yang ditekuni oleh Kepala Rumah Tangga Perempuan yang menjadi kelompok sasaran program iniyang tujuan akhirnya memberdayakan kelompok sasaran program ini mencapai tarap hidup yang mandiri, dan sejahtera.
\end{abstract}

Kata Kunci: Kemiskinan, Kelompok sasaran, Pemerintahan Desa.

Abstract: As known that poverty problem becomes the main problem of the central government to the regional government to overcome or reduce the poverty, until finally produced a program that called Jalan Lain Menuju Mandiri dan Sejahtera (JALIN MATRA) targeted to a group of womens as the head of family.This Provincial Government Program's aim is to carry out development that focuses on the poor, that targeted to the women as head of household.This research uses qualitative methods, data collection techniques: observation, interview and documentation. Informant determination technique: purposive sampling. Data analysis: through data reduction, data presentation, and conclusion /verification. Techniques to test data validity: triangulation.The results of this study indicate: the role of village government to overcoming poverty by implementing JALIN MATRA Program supported by funding / budget, facilities and infrastructure in form of equipment that accordance with the carried out business by the targeted household and the ultimate goal is to empower the target group of this program to achieve an independent and prosperous life plan.

Keywords: Poverty, Target groups, Village Government.

\section{PENDAHULUAN}

Undang-undang Dasar 1945 merupakan pedoman dasar yang harus dijadikan acuan untuk ditetapkannya aturan perundang-undangan selanjutnya, dalam pasal 34 Ayat (1): Fakir miskin dan anak-anak yang terlantar dipelihara oleh Negara, dari pasal ini menunjukkan bahwa persoalan kemiskinan menjadi tugas dan tanggungjawab Negara kepada rakyatnya. Upaya pemerintah menanggulangi persoalan kemiskinan ini selalu dilakukan baik dari masa yang lalu 
hingga ke masa kini, sebagai contoh dengan dikeluarkannya Program Jalan Lain Menuju Mandiri Dan Sejahtera (JALIN MATRA)secara spesifik diperuntukkan untuk mengatasipermasalahan kemiskinan di berbagai daerah di wilayah Negara Kesatuan Republik Indonesia.Dengan kebijakan pemerintah yang berbentuk programJalan Lain Menuju Mandiri Dan Sejahtera inibertujuan untuk menanggulangi kemiskinanyang terjadi di Negara Indonesia.

Kebijakan penanggulangan kemiskinan yang berwujud Program Jalan Lain Menuju Mandiri Dan Sejahtera (JALIN MATRA) ini senada dengan kebijakan Pemerintah Provinsi Jawa Timur yang dituangkan pada Rencana Pembangunan Jangka Menengah Daerah Provinsi Jawa Timur (RPJM-Provinsi Jatim) yang berorientasi pada penyelesaian masalah kemiskinan yang dihadapi masyarakat miskin (pro poor growth), dan pengarusutamaan gender. Hal ini menjadi konsentrasi pemerintah pusat, dengan mendelegasikan kewenangan dan pendanaan kepada pemerintah daerah di provinsi maupun pemerintah daerah di kabupaten/kota, bahkan ke level pemerintah desa/kelurahan untuk mewujudkan pengarusutamaan gender (PUG) atau kesetaraan gender.

Pengarusutamaan genderini oleh pemerintah pusat disosialisasikan kepada pemerintah daerah untuk menciptakan suatu strategi yang tepat, baik oleh pemerintahsendiri ataupun dengan organisasi lain yang relevan, untuk memastikan bahwa adanya aksi diberbagai area kritis tersebut dapat dilaksanakansecara efektif (Susiana, 2015:1). Pada sisi yang lain, di Negara Indonesia yang ratusan tahun dijajah oleh belanda menjadikan budaya patriarki masih melekat pada masyarakat Indonesia umumnya di semua wilayah. Makna Budaya patriarki ini adalah dimana budaya kaum laki-laki memiliki kedudukan lebih tinggi dibandingkan dengan kaum perempuan.

Budaya patriarkitersebutmasih sanggat dominan di Negara Indonesia hinggasekarang. Salah satu perbedaan yang menyolok dalam budaya patriarki ini,yakni adanya perbedaan yang jelas tentang tugas, dan peran, kaum laki-laki dan kaum perempuan dalam kehidupan sehari-hari di masyarakat, dan dilingkungan keluarga khususnya. Dimana kaum laki-laki sebagai pemimpin / kepala keluarga memiliki otoritas yang kuat untuk memimpin sumber daya ekonomi keluarga, kondisi ini menyebabkan peran kaum perempuan menjadi lebih sedikit terkait dengan akses dalam sektor publik, di bandingkan dengan kaum laki-laki. (Ermaningsih \&Samawati, 2014:111).

Dengan mengakarnya budaya tersebut hingga kini pemerintah menyadari adanya dampak yang serius terhadap kaum perempuan di wilayah Negara Indonesia, apalagi dampak kemiskinan yang dialami oleh kaum perempuan selanjutnyaPemerintah di Negara Indonesia dengan mengadopsi instruksi resmi Persatuan Bangsa-Bangsa terkait dengan pengarusutamaan gender ini, maka isu gender ini dimasukkan kedalam strategi pembangunan khususnya di bidang pemberdayaan perempuan. Selanjutnya ditindaklanjuti dengan keluarnya Peraturan Menteri Dalam Negeri Nomor 15 Tahun 2008 Tentang Pedoman Pelaksanaan Pengarus Utamaan Gender (PUG) di Daerah. Berikutnya dilakukan revisi dengan keluarnya Peraturan Menteri Dalam Negeri (PERMENDAGRI) Nomor 67 Tahun 2011 Tentang Pedoman Pelaksanaan Pengarus Utamaan Gender (PUG) di Daerah. Serta dalam pelaksanaannyaPengarus Utamaan Gender ini didukung dengan keluarnya Surat Edaran (SE) tentang Strategi Nasional Percepatan Pengarusutamaan Gender melalui Perencanaaan dan Penggangaran yang Responsif Gender (PPRG). Pada Tanggal 1 November 2012 dengan dikeluarkanya Surat Edaran bersama-sama Menteri Dalam Negeri (SE-MENDAGRI) Nomor: 050/6199/SJ. PadaTanggal 10 September 2013, yang ditunjukan kepada seluruh Gubernur di wilayah Negara Indonesia. 
Surat edaran menteri tersebut langsung direspon oleh pemerintah daerah, salah satu contohnya pada pemerintah Provinsi Jawa Timur bentuk komitmen Pengharusutamaan Gender ini dimasukkan dalam kebijakan strategis, dengan mengeluarkan Peraturan Daerah Provinsi Jawa Timur Nomor 3 Tahun 2014 Tentang Rencana Pembangunan Jangka Menengah Daerah (RPJMD) Provinsi Jawa Timur Tahun 2014-2019. Untuk menjamin dilaksanakannya Pengharusutamaan Gender inidi seluruh wilayah Jawa Timur baik pada Pemerintah kabupaten/kota, maka pemerintah Provinsi Jawa Timur menetapkan Peraturan Gubernur Jawa Timur (PERGUB-JATIM) Nomor 13 Tahun 2016 Tentang Pedoman Umum Program Jalan Lain Menuju Mandiri Dan Sejahtera (JALIN MATRA). Kota Batu merupakan salah satu wilayah pemerintah daerah yang berada di wilayah Provinsi Jawa Timur dengan Jumlah penduduk pada akhir tahun 2017 adalah 204.00 jiwa, (https://batukota,bps.go.id).

Permasalahan kemiskinan menjadi perhatian utama di wilayah Provinsi Jawa Timur, hal ini juga dirasakan oleh Pemerintah Kota Batu khususnya kemiskinan yang dialami oleh Kepala Rumah Tangga Perempuan, oleh karena itu dikeluarkannya Peraturan Gubernur Jawa TimurNomor 13 Tahun 2016 Tentang Pedoman Umum Program Jalan Lain Menuju Mandiri Dan Sejahtera (JALIN MATRA). Peraturan ini, menjadi pedoman dalam menanggulangi masalah kemiskinan dengan menjalankan Program Jalan Lain Menuju Mandiri Dan Sejahtera. Program ini substansinya adalah melakukan Pemberdayaan terhadap kaum perempuan, diawali dengan perencanaan program, penentuan anggaran, dan pemilihan pendamping atau tim pendamping beserta anggaran, serta didukung oleh aparatur pemerintah desa yang berusaha responsif pada kepentingan perempuan. Dalam pelaksanaan program ini, pemerintah Desa Pendem yang berada di wilayah Kecamatan Junrejo Kota Batu dituntut kerjasamanya dengan tim pendamping dan Kepala Rumah Tangga Perempuan yang sudah ditentukan,dengan tujuan untuk mencapai tarap hidup yang mandiri, dan sejahtera. Hal ini senada dengan Teori Peran oleh Soerjono Soekanto (2015:211) yang menyatakan bahwa peran sebagai konsep tentang apa yang dilakukan oleh individu dalam Masyarakat.

\section{METODE PENELITIAN}

Jenis penelitian ini kualitatif (Moleong 2014), Sumber data utama adalah sumber data primer, dan sumber data pendukung adalah sumber data sekunder (Sugiyono, 2017), teknik pengumpulan data dengan menggunakan wawancara, pengamatan, dan dokumentasi. Teknil analisis data yang dilakukan dengan model interaktif Milles dan Hubermans dengan langkahlangkahnya: - Reduksi data ini merupakan rangkuman atau menyederhanakan data dengan cara memilih-milah halhal yang dianggap pokok, sehingga dapat memberikan gambaran yang lebih jelas, serta memudahkan peneliti melakukan pengumpulan data berikutnya; - Penyajian data ini dilakukan setelah reduksi data selesai dilakukan, dalam penelitian kualitatif penyajian data ini bisa dilakukan dalam bentuk seperti: bagan, uaraian singkat, flowchart, hubungan antar kategori, dan lain-lain sejenisnya. Dengan penyajian data ini, maka data akan terorganisir, tersusun pada pola hubungan yang teratur, sehingga dengan mudah dapat di pahami;- penarikan kesimpulan atau verifikasi adalah langkah ketiga atau terakhir dalam analisis data kualitatif, menjelaskan bahwa penarikan kesimpulan ditunjukan untuk mendeskripsikan ataupunmenggambarkan suatu objek penelitian yang awalnya belum jelas,namun setelah diteliti menjadi jelas.Teknik keabsahan data dengan menggunakan triangulasi. 


\section{HASIL DAN PEMBAHASAN}

Peran Pemerintahan Desa Menanggulangi Kemiskinan Dengan Program Jalan Lain Menuju Mandiri Dan Sejahtera Yang Berhubungan Dengan Posisi Atau Tempat

- Peran Pemerintahan Desa Pendem dalam sebuah organisasi, harus dijalankan secara efektif sesuai dengan tugas dan fungsi yang diatur dalam peraturan perundang-undangan, pelaksanaan Program Jalin Matra dalam menanggulangi kemiskinan dengan program jalin matra menuju mandiri dan sejahtera di Desa Pendem berjalan efektif sesuai dengan kebutuhan, dan kemampuan usaha yang dimiliki oleh Kepala Rumah Tangga Perempuan sebagai kelompok sasaran;

- Peran Pemerintahan Desa Pendem berdasarkan hubungan denganposisi atau tempat di Desa Pendem yang berhubungan dengan kemiskinan warga / masyarakat yang menjadi kelompok sasaran Kepala Rumah Tangga Perempuan, hal ini sangat penting dilakukan untuk mewujudkan suatu perubahan yang continue / berkelanjutan untuk jangka panjang;

- Peran Pemerintahan Desa Pendem bertanggungjawab melaksanakan program Jalin Matra menuju mandiri dan sejahtera, kepada Kepala Rumah Tangga Perempuan sebagai kelompok sasaran. Serta bertanggungjawab melaksanakan program Jalin Matra menuju mandiri dan sejahtera di Desa Pendem.

- Peran Pemerintahan Desa Pendemmemberdayakan Kepala Rumah Tangga Perempuan sebagai kelompok sasaranuntuk menanggulangi kemiskinan melalui program Jalin Matra, agar mampu mencapai tarap kehidupan yang mandiri, dan sejahtera.

\section{Peran Pemerintahan Desa Pendem Menanggulangi Kemiskinan dengan Program Jalin Matra Menuju Mandiri dan Sejahtera}

- Peran Pemerintahan Desa Pendem dalam menanggulangi kemiskinan dengan Program Jalin Matra;

- Peran Pemerintahan Desa Pendem Bertangungjawab secara penuh dalam pemberdayaan masyarakat terkait dengan Program Jalin MatraMenuju Mandiri Dan Sejahtera di Desa Pendem;

- Peran Pemerintahan Desa Pendem merupakan faktor yang penting untuk mendukung pelaksanaan Program Jalin Matra dalam menanggulangi kemiskinan dengan program jalin matra menuju mandiri dan sejahtera di Desa Pendem;

- Peran Pemerintahan Desa Pendembertujuan untuk menanggulangi kemiskinan Dengan Program Jalan Lain Menuju Mandiri Dan Sejahtera padakelompok sasaran Kepala Rumah Tangga Perempuan.

Peran Pemerintahan Desa Menanggulangi Kemiskinan Dengan Program Jalan Lain Menuju Mandiri Dan Sejahtera, Sebagai Perilaku Yang Penting Bagi Struktur Sosial Masyarakat

- Peran Pemerintahan Desa Pendem yangberkedudukan sebagai sebuah instansi yang harus menjalankan Program Jalan Lain Menuju Mandiri Dan Sejahtera (JALIN MATRA)sesuai dengan tugas dan fungsinya, oleh karenanya Pemerintahan DesaPendem bertindak terhadap Program Jalan Lain Menuju Mandiri Dan Sejahtera (JALIN MATRA) ini dengan menggunakan keterampilan, dan pengetahuan yang dimiliki oleh aparaturnya.

- Peran Pemerintahan Desa Pendem yang berkedudukan sebagai sebuah instansi yang harus menjalankan Program Jalan Lain Menuju Mandiri Dan Sejahtera (JALIN MATRA) 
diperkuat dengan Perilaku aparatur dalam fungsi interaksi dengan Kepala Rumah Tangga Perempuan sebagai kelompok sasaran.

\section{Peran Pemerintahan Desa Menanggulangi Kemiskinan Dengan Program Jalan Lain Menuju Mandiri Dan Sejahtera, Suatu Konsep Tentang Apa Yang Dilakukan Dalam Suatu Organisasi}

- Peran Pemerintahan Desa Pendem Menanggulangi Kemiskinan Dengan Program Jalan Lain Menuju Mandiri Dan Sejahtera, yang berkaitan dengan konsep apa yang dilakukan dalam suatu organisasi pemerintah desa dalam menyelenggarakan Program Jalin Matra ini selalu mengacu atau berpedoman pada Peraturan Gubernur Jawa Timur Nomor 13 Tahun 2016 Tentang Pedoman Umum Program Jalan Lain Menuju Mandiri Dan Sejahtera (JALIN MATRA). Dengan demikianperan Pemerintah Desa Pendem memberikan fasilitas sarana, dan prasarana seperti;memberikan fasilitas berupa alat-alat yang dibutuhkan oleh Kepala Rumah Tangga Perempuan sebagai kelompok sasaran untuk mengembangkan usaha yang dimilikinya menjadi penting, karena berjalannya program Jalin Matra inidiperlukan peran Pemerintahan Desa Pendem.

- Peran Pemerintahan Desa Pendem ini dengan Program Jalin Matra bisa mengurangi angka kemiskinan, yang dialami Kepala Rumah Tangga Perempuan sebagai kelompok sasaran. Secara kongkrit Pemerintah Desa Pendem memberikan batuan berupa pemberian barangbarang sebesar Rp.2.500.000. (Dua Juta Lima Ratus ribu Rupiah)untuk setiap kelompok sasaran, yang dipergunakan untuk meningkatkan kegiatan usaha ekonomi produktif yang berupa modal investasi,berbentuk sarana-prasarana usaha, dan berupa modal minimal 70\% (Tujuh Puluh Persen), serta berupa bantuan bahan makanan yang bisa memberikan kontribusi untuk pemenuhan kalori, dan penurunan beban pengeluaran kelompok sasaran sebesar 10\% (Sepuluh Persen), serta kegiatan usaha pendukung lainnya seperti:usaha ternak (bebek), pertanian karangkitir (rumah pangan lestari), dan lain sebagainya yang diperkirakan 20\% (Dua Puluh Persen).

\section{Faktor Pendukung}

Peraturan perundang-undangan, Struktur organisasi Pemerintahan Desa, Sarana dan Prasarana, sumber pendanaan, kerjasama yang baik antara aparatur dan tim pendamping, aparatur pemerintahan desa pendem, alokasi anggaran, bantuan sarana prasarana, dan partisipasi Kepala Rumah Tangga Perempuan sebagai kelompok sasaran Program Jalan lain Menuju Mandiri dan Sejahtera (JALIN MATRA).

\section{Faktor Penghambat}

Kurang sesuainya identitas kelompok sasaran, dan Rendahnya Sumber Daya Kepala Rumah Tangga Perempuan sebagai kelompok sasaran Program Jalan lain Menuju Mandiri dan Sejahtera (JALIN MATRA).

\section{KESIMPULAN}

1. Peran Pemerintahan Desa Pendem dijalankan secara efektif sesuai tugas dan fungsi yang diatur dalam peraturan, sesuai kebutuhan, dan kemampuan usaha kelompok sasaran; serta bertanggungjawab, dan memberdayakan kelompok sasaranuntuk menanggulangi kemiskinan, agar mampu mencapai tarap kehidupan yang mandiri, dan sejahtera. Serta berkedudukan sebagai sebuah instansi sesuai dengan tugas dan fungsinya, bertindak dengan 
menggunakan keterampilan, dan pengetahuan yang dimiliki oleh aparaturnya, diperkuat dengan Perilaku aparatur dalam fungsi interaksi dengan kelompok sasaran, dengan pedoman pada Peraturan Gubernur Jawa Timur Nomor 13 Tahun 2016, bisa mengurangi angka kemiskinan,kelompok sasaran. Dengan memberikan batuan berupapemberian barangbaranguntuk setiap kelompok sasaran, yang dipergunakan untuk meningkatkan kegiatan usaha ekonomi produktif yang berupa modal investasi,berbentuk sarana-prasarana usaha, dan berupa bantuan bahan makanan serta kegiatan usaha pendukung lainnya: usaha ternak (bebek), pertanian karangkitir dan lai-lain.

2. Faktor pendukung: Peraturan perundang-undangan, Struktur organisasi, Sarana dan Prasarana, sumber pendanaan, kerjasama yang baik antara aparatur dan tim pendamping, dan partisipasi kelompok sasaran. Faktor Penghambat: Kurang sesuainya identitas kelompok sasaran, dan Rendahnya Sumber Daya kelompok sasaran.

\section{DAFTAR PUSTAKA}

Ernanigsih, W., \& Sasmawati, P.(2014). Pengaruh Budaya Patriarki terhadap perceraian. Malang : Penerbit Tunggal Mandiri.

https://batukota.bps.go.id/data jumlah penduduk berdasarkan kecamatan dan Kota Batu 2017.

Moleong, J. Lexi.2014. Metodologi Penelitian Kualitatif: PT Remaja Rosdakarya Bandung.

Peraturan Gubernur Jawa Timur Nomor 13 Tahun 2016 Tentang Pedoman Umum Program Jalin Matra.

Peraturan Menteri Dalam Negeri Nomor 67 Tahun 2011 Tentang Pedoman Pelaksanaan Pengarus Utamaan Gender (PUG) di Daerah.

Peraturan Mentri Dalam Negeri Nomor 15 Tahun 2008 Tentang Pedomana Umum Pelaksana Pengarusutamaan Gender dalam Pembangunan di Daerah.

Rencana Pembangunan Jangka Menengah Daerah (RPJMD) Provinsi Jawa Timur Tahun 20142019.

Soerjono Soekanto.2015. Sosiologi Suatu Pengantar: PT Rajagrfindo Persada. Jakarta

Sugiyono. 2017. Metode Penelitian Kualitatif, Kualitatif Dan R\&D :Alfabeta CV Bandung

Surat Edaran bersama-sama Menteri Dalam Negeri Nomor: 050/6199/SJ. PadaTanggal 10

September 2013, yang ditunjukan kepada seluruh Gubernur di wilayah Negara Indonesia.

Susiana,S.(20015). Penerapan Konsep Perencanaan dan penggangaran Responsif Gender (PPRG) dalam membangun Daerah (Studi di Provinsi Papua dan di Daerah Istimewa Yogyakarta. Jakarta :Pusat Pengkajian, Pengolahan Data dan Informasi (P3DI) Sekretariat Jendral DPR RI.

Undang-Undang Dasar 1945 